\title{
Effect of the knife-incising pretreatment on the surface checks occurrence of red pine heavy timber after drying
}

\author{
Chang Jin Lee ${ }^{1} \cdot$ Seung Won $\mathrm{Oh}^{1} \cdot$ Nam Ho Lee ${ }^{1} \cdot$ Chun Won Kang ${ }^{2}$
}

Received: 30 July 2015/Published online: 24 October 2016

(c) The Author(s) 2016. This article is published with open access at Springerlink.com

\begin{abstract}
The aim of this study was to investigate the effect of the knife-incising pretreatment on the surface checks occurrence of red pine heavy timber after drying. The effect of knife-incising was evaluated by comparison with surface checks which occurred in the control and kerfed material. The results revealed that the knife-incising treatment was effective compared with control in the prevention of surface checks, and the effect is similar to that of the kerfing treatment. In addition, the combination of incising and kerfing was most effective in preventing surface checks.
\end{abstract}

\section{Introduction}

Red pine (Pinus densiflora S. et Z) wood is commonly used to build Korean traditional houses and as building material in form of posts, beams, and rafters. In particular, heavy timbers such as posts and beams should be dried properly in order to prevent deformation after construction. However, during drying of heavy timbers surface checks often occur and negatively influence the appearance of the building after construction. Consequently, various methods such as high-temperature and low-humidity pretreatment, incising $\left(\mathrm{CO}_{2}\right.$ laser$)$, and longitudinal kerfing have been tested (Hattori et al. 1997; Lee et al. 2013; Listyanto et al.

Seung Won Oh

ohsw@jbnu.ac.kr

1 Department of Wood Science \& Technology, Chonbuk National University, 567 Baekje-daero, deokjin-gu, Jeonju-si, Jeollabuk-do 54896, Korea

2 Department of Housing Environmental Design, Chonbuk National University, 567 Baekje-daero, deokjin-gu, Jeonju-si, Jeollabuk-do 54896, Korea
2013). Among the incising methods, knife-incising by introducing artificial scars on the four surfaces of the timber, makes it possible to evenly distribute the stress on all surfaces. Therefore, the knife-incising treatment was assumed to be the best method to protect the surface from check occurrence by dispersing the stress during the drying. However, there have been no studies relating to the effect of the knife-incising treatment on surface checks so far. Thus, in this study, knife-incising pretreatment was applied, and after drying, the effect of knife-incising on the surface checks occurrence was evaluated by comparison with the surface checks occurred in the control and kerfed material.

\section{Materials and methods}

Red pine heavy timber with dimensions of $20 \times$ $20 \times 360 \mathrm{~cm}^{3}$ was used in this study. Prior to drying, the heavy timbers were treated with knife-incising (Inc), longitudinal kerfing (Ker) and a combination of knife-incising and longitudinal kerfing (Inc-Ker). The knife-incising treatment was carried out on all four sides $\left(2400\right.$ piece $\left./ \mathrm{m}^{2}\right)$ (Fig. 1b). After that, kerfing treatment was processed by using a circular saw (Fig. 1a). Untreated timber was used as a control (Con). Five specimens were prepared for each condition.

Drying test was carried out using a commercial dryer under conditions as follows: (1) steaming (dry-bulb $95{ }^{\circ} \mathrm{C}$, wet-bulb $95{ }^{\circ} \mathrm{C}, 12 \mathrm{~h}$ ), (2) high-temperature and low-humidity pretreatment (dry-bulb $120^{\circ} \mathrm{C}$, wet-bulb $90^{\circ} \mathrm{C}$, $48 \mathrm{~h}$ ), (3) elevated temperature drying (dry-bulb $90^{\circ} \mathrm{C}$, wet-bulb $70{ }^{\circ} \mathrm{C}, 144 \mathrm{~h}$ ). Distance between crossers and spacing between specimens were adjusted to 60 and $3 \mathrm{~cm}$, respectively. 


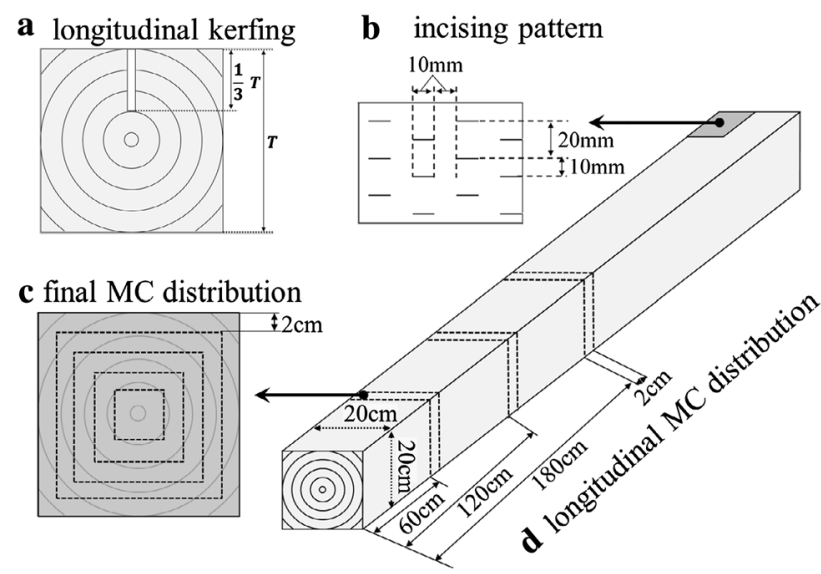

Fig. 1 Processing diagram of the specimens (a longitudinal kerfing, b knife-incising, c final MC distribution, d longitudinal MC distribution)

At the end of drying, number, length, and width of surface checks present on the surface of all dried specimens were measured ( $>2-\mathrm{mm}$ check width). From these results, average number of surface checks (ANS) and average length of surface checks (ALS) were determined. Average area of surface checks (AAS) was calculated by the following formula:

$\mathrm{AAS}=\frac{\sum_{1}^{n} l_{i} \times w_{i}}{2 N}$

where, $l$ length of each surface check, $w$ width of each surface check, $n$ total number of checks with width $>2 \mathrm{~mm}, \mathrm{~N}$ number of specimens. In this formula, the denominator was set to ' 2 ', because the checks have a diamond shape.

The analysis was carried out by one-way analysis of variance (ANOVA) (at $\rho<0.05$ ). After that, Tukey-Kramer Honestly significant difference (HSD) test was used for post-mortem analysis (at $\rho=0.05$ ).

One specimen selected from each pretreatment condition was used for the measurement of final moisture content and distribution. The moisture content (MC) was determined by the oven-dry method (at $103 \pm 2{ }^{\circ} \mathrm{C}$ ). The MC samples were obtained at the position of 60,120 , and $180 \mathrm{~cm}$ from the end surface (Fig. 1d) and cut as shown in Fig. 1c.

\section{Results and discussion}

\subsection{Final moisture content and distribution}

After drying, density changed from 597-687 to $433-508 \mathrm{~kg} / \mathrm{m}^{3}$ and MC was reduced from $41.7-58.9$ to 9.1-10.3\%. However, a slight moisture gradient from the surface (around 6\%) to the core (around 20\%) was observed in all specimens. Although the kerfing and knifeincising did not affect the drying rate during timber drying (Jung et al. 1997), it may reduce the moving distance of water from the core to the surface. However, the obtained results showed that there was no difference of $\mathrm{MC}$ in an adjacent part to the surface.

\subsection{Surface checks}

ANS of Inc (15.2 number/piece) was less than ANS of Con (24.6 number/piece) (Table 1). Similarly, ANS of Inc-Ker (5.2 number/piece) was less than ANS of Ker (16.8 number/piece). It can be interpreted that the knife-incising treatment prevents surface checks occurrences through the dispersion of stress on all four sides.

ANS, ALS, and AAS of Inc were less than those of Con, and similar to those of Ker. This means that with the knifeincising treatment it was possible to decrease or to more evenly distribute the formation of stress. Thus, the knifeincising treatment was considered to be effective in the prevention of surface checks.

\subsection{Statistical analysis}

One-way ANOVA was performed to verify that the differences in ANS, ALS, and AAS depending on pretreatment conditions were significant. As a result, the occurrence of surface checks according to pretreatment conditions were significantly different among the four sample groups (Con, Inc, Ker, and Inc-Ker) according to ANOVA (ANS, ALS, and AAS $\rho<0.05$ ) (Table 1; Fig. 2). ANS varied for the occurrence of surface checks

Table 1 Statistical analysis results for ANS, ALS, and AAS

\begin{tabular}{lllr}
\hline Dependent variable & Pretreatment & N & Mean \\
\hline ANS* (number/piece) & Con & 5 & 24.60 \\
& Inc & 5 & 15.20 \\
& Ker & 5 & 16.80 \\
& Inc-ker & 5 & 5.20 \\
ALS* $(\mathrm{cm} /$ piece) & Con & 5 & 665.24 \\
& Inc & 5 & 418.00 \\
& Ker & 5 & 367.60 \\
& Inc-ker & 5 & 156.80 \\
AAS* $\left(\mathrm{cm}^{2} /\right.$ piece $)$ & Con & 5 & 87.40 \\
& Inc & 5 & 54.58 \\
& Ker & 5 & 29.30 \\
& Inc-ker & 5 & 18.36 \\
& &
\end{tabular}

$N$ number of specimens

$* \rho<0.05$ 

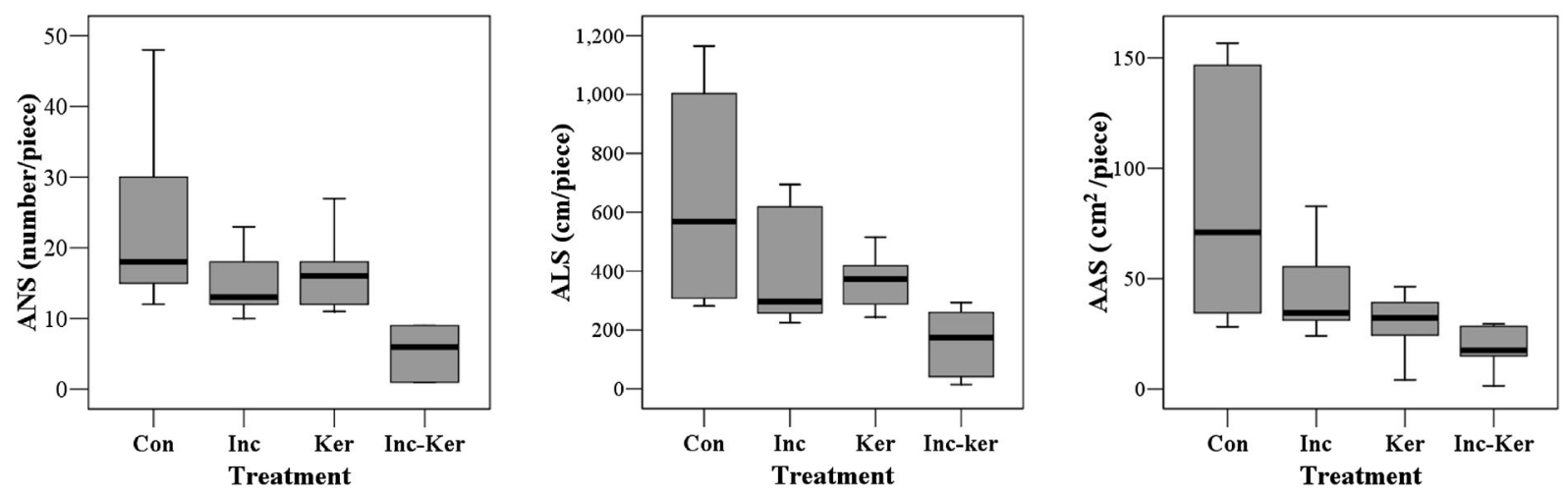

Fig. 2 Mean and standard deviation of ANS, ALS, and AAS

according to pretreatment conditions; Con ( $\mathrm{M}=24.6$, $\mathrm{SD}=14.758)$ had the highest ANS, followed by Ker $(\mathrm{M}=16.8, \mathrm{SD}=6.38)$, Inc $(\mathrm{M}=15.2, \mathrm{SD}=5.263)$, and Inc-Ker $(\mathrm{M}=5.2, \mathrm{SD}=4.025)$.

As a result of post-mortem analysis, Inc-Ker produced statistically significantly fewer surface checks than Con (ANS, ALS, and AAS $\rho<0.05$ ). Except for the relation between Con and Inc-Ker, statistically significant differences in the other cases did not exist. However, in the case of Inc and Ker, all p-values were close to 1 . It can be interpreted that Inc and Ker have a similar effect. The knife-incising treatment is considered to contribute to the prevention of surface checks at the same level as kerfing; differences between the two pretreatments were not statistically significant.

In this study, all p-values, except for the comparison of Con and Inc-Ker, were higher than 0.05. When the specimen quantity is small, statistical analysis is meaningless. Therefore, these results are assumed to be due to (1) the lack of specimen quantity, and (2) non-uniformity of the properties of wood materials. Even though, the statistical significance is insufficient, it is likely to confirm the trend.

\section{Conclusion}

In this study, the following results were obtained: (1) pretreatment did not influence the final moisture content and moisture content distributions. (2) Knife-incising treatment was effective in preventing surface checks. ANS, ALS, and AAS of Inc were less than that of Con. The effect of Inc on the reduction of surface checks occurrence was similar to that of Ker. (3) Inc-Ker was most effective in preventing surface checks and produced statistically significantly fewer surface checks than Con $(\rho<0.05)$.

Acknowledgements Financial support was provided by the "Leaders in Industry-university Cooperation" Project, supported by the Ministry of Education, Science \& Technology (MEST) and the National Research Foundation of Korea (NRF).

Open Access This article is distributed under the terms of the Creative Commons Attribution 4.0 International License (http:// creativecommons.org/licenses/by/4.0/), which permits unrestricted use, distribution, and reproduction in any medium, provided you give appropriate credit to the original author(s) and the source, provide a link to the Creative Commons license, and indicate if changes were made.

\section{References}

Hattori N, Ando K, Kitayama S, Kubo T, Kobayashi Y (1997) Application of laser incising to microwave drying of sugi square lumber with black-heart. For Res Environ 35:53-60

Jung HS, Lee NH, Park JH (1997) The characteristics of vacuum drying heated by hot plates for the thinned logs and pillars of Korean pine (in Korean). Mokchae Konghak 25(4):51-60

Lee CJ, Lee NH, Eom CD, Shin IH, Park MJ, Park JS (2013) Effect of end-coating around pith of heavy timbers of red pine and Korean pine on high-temperature and low-humidity drying characteristics. J Korean Wood Sci Tech 41(3):221-233

Listyanto T, Ando K, Yamauchi H, Hattori N (2013) Microwave and steam injection drying of $\mathrm{CO} 2$ laser incised Sugi lumber. J Wood Sci 59(4):282-289 